\title{
The Contribution of ICT in Higher Education: a multifaceted approach
}

\author{
Suhail Anwar ${ }^{1}$ Dr. Sibichan K. Mathew ${ }^{2}$ \\ ${ }^{I}$ National institute of Fashion Technology, India \\ ${ }^{2}$ National institute of Fashion Technology, India
}

\begin{abstract}
Information and Communication Technologies (ICTS), embrace many technologies that enable the users to receive and send information; making it convenient for the users to communicate or exchange information with others. ICT contributes in education in many ways such as: ICT as a collaborative tool, ICT as a tool to support traditional subjects, ICT as an administrative tool and many more. In teaching and learning, the use of ICT lies in putting in place ICT equipments and tools.

In case of higher education, ICT has more prominent role to play and it is growing at an unprecedented rate. The newer kinds of software and technologies are being introduced for cohesive integration. Technology in classroom today includes the same kinds of tools that professionals use in their work places. Employers now demand that graduating students must equip with latest technologies to meet the requirements of the industry efficiently and effectively. ICT therefore is significantly contributing to the productive learning and quality enhancement in the education world. Though, more advancement and adaptation in this area is yet to happen. This article is an attempt to summarize the contribution of ICT in the Higher Education by careful examination of facts.
\end{abstract}

\section{Introduction}

Education is one of the major contributors to economic well being and progress of mankind. Education is becoming a major source of competitive advantage when global economic competition is growing sharper. It facilitates economic growth and helps a country to attract jobs and investments. Education, moreover, is one of the prime factors that determine lifetime earnings. It is said, the route to tackling a nations poverty and attaining financial independence is , therefore, through educational attainment. As per the Nobel Laureate Amritya Sen, it is the root cause of most of the problems; developing countries like India are facing today.

With the passage of time, a lot of changes have taken place in the field of education technology. Particularly with the advent of Information technology there has been a sea change in almost every sphere of our lives. With Information technology turning more user friendly and robust, academic activities in higher education are adopting the use of ICT in their day to day functioning. In order to make teaching and learning more effective than ever, management systems assist instructors in integrating technology into their respective domains. Online communication and information access expands a horizon of education to wherever and whenever an instructor or student wants it. A higher bandwidth facilitates to achieve this in a quicker and an efficient way. Due to introduction of newer technologies, classroom sessions are being replaced with virtual sessions or traditional classroom courses are being substituted with online courses.

\section{ICT and Education}

UNESCO defines Information and Communication Technologies (ICT) as technologies that help create, propagate and exchange information. This definition includes various tools of communication / multimedia, old and new. For instance, television, telephone, satellite systems, computer network, software and, associated services and equipments such as e-mail, videoconferencing etc.

The pioneering step towards ICT in education was taken by Stanford University psychology professors Patrick Suppes and Richard C Atkinson in 1960s when researchers explored, in elementary school, the prospects of using computers to learn math and reading to children. These steps flourished when William D. Graziadei , in the year 1993 , through electronic mail described an online computer-delivered lecture, tutorial and assessment project. E-learning system's roles were considered to be conveying knowledge by endeavors for duplicating despotic teaching techniques. Progressively though, these systems are developing into means of shared development of knowledge based on Computer Supported Collaborative Learning (CSCL). Exhaustive work is being done to develop even better systems enthusiastically. However the education system faces a few focal challenges as well:

1. Access to education is an issue in India due to poor infrastructural, linguistic and physical barrier in the way of people who wish to have access to education (Bhattacharya and Sharma, 2007).

2. Quality of education seems to be a huge challenge due to lack of intellectual infrastructure and the meagre quality of teachers. 
3. The enduring obstacle to ICT implementation is lack of funds.

The ICTs in higher education may be used at different places though it may extensively be exploited to assist traditional subjects for better academic deliverance and overall output. ICTs can be used in collaborative learning for recuperating the quality of research particularly in India, and of course the role of ICTs in academic administration cannot be ruled out keeping in view of its vast contribution in enabling the academic establishments to maintain their standards and sustainability.

\section{a. ICT as a tool to support traditional subjects}

The instructors incorporate technology in some or all facets of his teaching. As said earlier, these technologies include various media and tools such as high end multimedia presentations, web-based activities, multimedia simulations, virtual labs, sophisticated software etc. Among the plenty, one of the foremost applications of ICT for teachers to use computer technology for making lecture notes. ICT can improve the learning process through the provision of more interactive teaching materials that increase learners' interest and acquisition of knowledge. ICT can enable teachers to renovate their teaching practices by providing them improved educational contents and teaching pedagogies. It has been established that on-line teaching aids and other educational materials provide significant contribution in academic development of teachers and the students. In case of professional education, students are being trained for employment and hence it is pretty beneficial for them to experience industrial processes. ICTs contribute in such simulations to equip the students with latest practices. Nowadays lot of industrial processes are being executed using sophisticated computer systems and it makes sense to train the students about these latest processes during their education to bring them at par with the requirements of the industry. Several E-lectures are easily modifiable and shared. With respect to many concepts, visual aids enjoy a great role in making concepts clear to students. Without which, it is difficult to connect to the concept. ICT can make substantial improvement in teaching-learning process. It is never argued that ICT can replace teachers but it is a great aid for academic deliverance and gaining of higher education.

\section{b. ICT as a tool for collaborative learning}

In developing countries, educational access is a biggest challenge. The quality of research may be enhanced by collaborative learning with the developed countries. The internet is the main supporting infrastructure for ICTs. The platform it provides is tremendous e.g. e- libraries, virtual portfolios, online education, cyber infrastructure etc. are some of the worthwhile instances of ways to spread education through elearning. Such components create a platform where all stakeholders including instructors and students can connect.

Additionally, a number of established universities offer distance mode of delivery. Usually, the goal is to broaden access to markets where traditional approaches don't thrive. In such scenario, universities at times offer the same course as a hybrid that is delivered online and through traditional classroom methods. Yet another approach is to open satellite campuses with high speed internet connectivity which enables the students living in smaller towns to get access to education which otherwise would not have been probable. Occasionally, distant learning bears the advantage of reaching students parked in remote places of a country there by providing them access to higher education. Many developing countries have the hybrid class of universities. For example, China has a history of the use of satellite television for delivery of education to its huge and distant population. The Government is well aware both of the need for university education and the distance education by using newer technologies.

However, particularly for developing nations, distribution expenditure can still be an arduous impediment. In order to facilitate distance education to accomplish its true potential in developing countries, economical and efficient communications are essential. Newer technologies such as Wi-Fi and VSAT are classic examples of low cost communication for the people of rural areas. Besides surfing, the students can listen to lectures through voiceover- IP applications which need less bandwidth than videoconferencing. Interactive communications will be enabled by new mobile devices which allow image and video transmissions. These new mobile devices will undoubtedly be used first in wealthier countries, like personal digital assistants (PDA) are already being deployed in teaching-learning process in developed countries.

ICTs also permit the making of digital wherewithal like digital libraries where students, researchers, teachers and professionals can gain easily access to research and course material irrespective of physical location and time (Bhattacharya and Sharma, 2007; Cholin, 2005). Such services permit the networking of academics and researchers and thus sharing of scholarly material. This in turn evades duplication of work. A platform for sharing information and knowledge is also granted by ICTs. This can chip in to the betterment of program delivery in terms of reproduction of best practices. For researches, it helps in information sharing and gathering, network building, access to resource material etc). The usage of ICT in education is turning out to be 
a necessity given that it develops skills of higher order such as solving complex real worlds problems and collaborating across time and place. The real time interaction in the various facets of education hold great potential for the future. The exposure a student gathers enhances his / her view of the world and helps in creating a most developed perception. Thus, ICT helps on preparing the required workforce for the knowledge economy.

\section{c. ICT as an Administrative tool}

The Campus management is one of the toughest jobs particularly when it grows in size and numbers. In present scenario where change happens at the rate of thought, it is next to impossible to sustain without the presence of technology. ICTs give students and teachers new tools with which to learn and teach in effective manner. ICTs extend opportunities to supervise, coordinate and to control day-to-day administrative activities of the academic institution in easy and transparent ways. It has been proven by a number of studies that application of ICTs in administrative services is the need of the hour. The areas in education administration where ICTs may play a significant role may depend upon the institutional requirements. Based on the literature review, the highlights of this category relate to usage of e-media for admission activities. This may include admission enquiry by students, applying for admissions through electronic media, registration / enrolment using computers, course allotment, and availability of information like timetable / class schedule in electronic form and attendance monitoring / maintenance through e-media. Having perused the various literature, it is felt that the use of ICTs in admission process, maintenance of student's personal and other academic records, submission of class assignments and projects, monitoring and evaluation, and communications with the stakeholders is unavoidable for sustainable development of the educational establishments.

\section{Conclusion}

Yet, the bottom line remains that without skilled instructors, no electronic means can bear fruit. Technology can never substitute good teaching but it can certainly help to make it more effective. The authors emphasize the notion of specific ICT uses and point out that the use of ICTs can definitely make phenomenal differences in teaching learning process in higher education particularly in India.

There are number of benefits one can derive out of ICT enabled teaching-learning. Quality improvement in overall delivery and learning is one of the most attractive elements of online learning. In fact, many online students find their educational journey rewarding and exciting with the use of newest technologies. One of the major benefit is that virtual classrooms can be accessed from anywhere in the world and it enables the instructor to virtually deliver the lecture anywhere across the globe. In current competitive scenario, the demand for higher education cannot be met without distance and virtual mode of learning.

ICT contributes in disseminating information irrespective of geographical boundaries. It disjoints information from physical location boundaries and thus integrates rural and remote communities in the global network of knowledge and culture. ICT facilitates and enhances the academic administration by providing realtime services for student admission, attendance, timetabling, examination and evaluation, announcement and submission of class assignments, use of specialized software and virtual labs through web applications and more.

ICTs application in teaching should be encouraged as it is indisputably a valuable tool. Still, to get the best of ICT several variables have to be duly maintained; including appropriately designed software and hardware, training, approach of instructors and the awareness that different students have different requirements. Application of ICT requires an exploratory attitude since it requires quite different pedagogical techniques from traditional classroom teaching. This can take a long time to formulate and propagate the concept of using ICT for academic enrichment. Properly devised ICTs can open doors of education for new factions of students and that would include particularly mature students, lifelong learners, and students with physical disabilities. It is firmly trusted that technology enabled courses might help in bridging the gap between some education and no education at all for people from remote locations. Therefore, it is principally worthwhile for aid donors to invest in prospects of remote learning.

\section{References}

[1]. Adam, S. (2001). Transnational Education Project. Report and Recommendations. Confederation of European Union Rectors' Conferences.

[2]. Annand, D. (1999) 'The problem of computer conferencing for distance-based universities', Open Learning, 14 (3), 47-52, p. 20.

[3]. Ashish Kumar and Arun Kumar (2005),'IT based KM for Institutions of Higher Education A Need", Paper published in A weekly Journal of Higher Education in India from Association of Indian Universities, New Delhi India Vol. 43, No. 30, July 25-31, 2005, pp. $4-9$

[4]. available through http://www.hefce.ac.uk/pubs/HEFCE/2000/00_44.htm

[5]. Ben-Zion Barta., et.al. (1995)," Information Technology in Educational Management", Chapman and Hall, London.

[6]. Caroline Salerno (2009),"Administrator's Role in Technology Integration”, Education World 2009. 
[7]. Christiana Maki (2008),'Information and Communication Technology for Administration and Management for secondary schools in Cyprus", Journal of Online Learning and Teaching Vol. 4 No. 3.

[8]. Collis, B \& M.C. van der Wende (Eds.) (1999). The Use of Information and Communication Technology in Higher Education. An International Orientation on Trends and Issues. Enschede: University of Twente /CHEPS.

[9]. Costello, N. (1993) 'Organisational cultures and distance learning', Open Learning, 8 (3),3-11.

[10]. Daniel, J.S. (1996). Mega Universities and Knowledge Media. Technology Strategies for Higher Education. London: Kogan Page.

[11]. Dhanarajan, R. (2001) 'Distance education: Promise, performance and potential', Open Learning 16 (1), 61-8, p. 67.

[12]. G. Morgan, Faculty Use of Course Management Systems (Boulder, Colo.: EDUCAUSE Center for Applied Research, 2003).

[13]. Gunmala Suri (2005)," "Organizational culture in ICT implementation and knowledge management in Spanish and Indian Universities: A conceptual Model", published in A Special Interest Groups of CSI.

[14]. Hillsberg, T. (2001). Paper presented at the CSHE Symposium "University Teaching as E-Business? Research and Policy Agendas".

[15]. Hossein Zainally (2008)," Administration of Faculties by Information and Communication Technology and Its Obstacles", International Journal of Education and Information Technologies, Vol. 2,issue1 2008

[16]. Kelly, K. (1998). New rules for the new economy: 10 radical strategies for a connected world. New York: Penquin.

[17]. Konrad Osterwalder, Under-Secretary-General of the United Nations Rector of the United Nations University, "The Role of Higher Education Institutions in Promoting Sustainable Development".Learning management system (LMS) and Learning content management system (LCMS), available at http \ www.wickipedia.com

[18]. Magni (2009),'ICT usage in Higher education”, International Technology and Education and Development Conference, Spain March 9-11 2009.

[19]. Malathi Sriram, Chairperson - PGDM, SDM Institute for Management Development, Mysore "E-Learning in Higher Education Issues, Challenges, Benefits \& Future: Brief Outline: e-Learning in Continuing Learning and Education" February-2010.

[20]. PricewaterhouseCoopers (2000) Business model for the e-University, Main report

[21]. Roblyer M.D. (2005),"Educational Technology Research That makes a Difference: Series Introduction, Contemporary issues in Technology and Teacher Education Vol.5, Issue 2(2005).

[22]. S. E. Metros and K. Bennett, "Learning Objects in Higher Education," ECAR Research Bulletin, Issue 19, Oct. 1, 2002.

[23]. Sharad Sinha(2008), National Policy on ICT in School Education, Ministry of Human Resource Development Government of India

[24]. Taylor, J.C. (2001). Fifth Generation Distance Learning. Keynote Address delivered at the 20th ICDE Conference, Dusseldorf, Germany, April 2001.

[25]. Thomas Kwaku Obeng (2004), "Practical Application Of ICT To Enhance University Education In Ghana", Feature Article, Ghana Web 2004. 